\title{
Chapter 7 \\ Political Impact of the Fukushima \\ Daiichi Accident in Europe
}

\author{
Mikael Jensen
}

\begin{abstract}
The description in this chapter mentions reactions in Europe on the Fukushima Daiichi accident, seen from the author's Swedish perspective, from the observation post offered by the Swedish Radiation Protection Institute, SSI (now the Swedish Radiation Safety Authority).
\end{abstract}

Keywords Fukushima impact in Europe - Past nuclear accidents • European nuclear policy

\subsection{Earlier Accidents}

When interpreting the reactions on the Fukushima Daiichi accident in Europeand elsewhere-it is valuable to know about some earlier accidents that affected people, notably the Three Mile Island and Chernobyl accidents. These accidents both had important impacts on popular views on nuclear power.

\subsubsection{The Three Mile Island Accident}

This accident was the first major accident in a civilian nuclear power plant. It occurred on Wednesday, March 28, 1979, in Three Mile Island, Dauphin County, Pennsylvania, near Harrisburg, United States. The containment was intact after

The author is retired and presently employed part time by the Swedish Vattenfall Company.

\footnotetext{
M. Jensen ( $\triangle)$

Swedish Radiation Protection Authority, Stockholm, Sweden

e-mail: jensen19@gmail.com 
the accident but a large amount of noble gases and some iodine was released. The official description of the consequences implied that the dose to individuals of the public most affected by the accident was marginally higher than the natural yearly dose. In the U.S., with its highly polarized nuclear debate, this has been disputed, but it was generally accepted by authorities in Europe. The general features of the official description of the release scenario would have been assumed in any case, based alone on the fact that the containment was intact and the absence of longlived nuclides outside the containment, leaving room only for some uncertainty about the amount of iodine released.

It was understood by the public that the releases would not threaten the safety of Europeans, but the fact that an accident had occurred in the motherland of nuclear power did trigger a general debate on the safety and wisdom of nuclear power production.

In Austria, a referendum half a year earlier had already led to a halt for nuclear power. This meant abandoning a newly built and licensed facility, the Zwentendorf Nuclear Power Plant, planned to produce $10 \%$ of Austria's power. The accident, therefore, did not directly affect the nuclear policy, other than preventing Austria from looking back on the nuclear power alternative.

In a somewhat similar way as Austria, Sweden had a debate before the TMI accident, but it was related to final disposal of the waste. In Sweden, a referendum on nuclear power was held in March 1980, with 3 different alternatives: (1) No, accompanied by a phase - out period of 10 years; (2) Yes, but with phase out as alternatives become available; and (3) with partly similar text as (2). The second option was different from the third in that it also had a provision that required public ownership of nuclear reactors and taxation of part of the generated profit, the "surplus profit." Alternatives 2 and 3 received a majority.

Also, a safety evaluation in Sweden lead the regulators, then SSI and SKI (The Swedish Nuclear Power Inspectorate), to require filtered containment venting systems for the Swedish reactors, to mitigate releases in an accident situation where the containment remained intact but with pressure build-up. The filters were required to stop $99.9 \%$ of any release, noble gases and iodine excluded.

In the rest of Europe the Three Mile Island accident triggered an intensive debate, in particular in Germany.

\subsubsection{The Chernobyl Accident}

The accident occurred April 26, 1986 and had an important impact on several European states. Doses were significant in around Chernobyl, and elsewhere in Ukraine, Belarus, Russia, and iodine tablets were distributed in Poland. In Western Europe, individual doses attributable to Chernobyl were low, at most in the region of a few $\mathrm{mSv}$ and national averages were very low, in Sweden $0.01 \mathrm{mSv}$. However, 
counter-measures were significant and included prohibition of selling and advice against consumption of several types of foodstuffs, including game, reindeer, and fish from certain lakes.

In Ukraine and Belarus, the incidence of thyroid cancer increased as a result of the accident. Until 2005, approximately 6,000 cases of thyroid cancer in children (of whom 15 have died) were considered attributable to the accident [1]. The collective dose was estimated to be around 0.5 million man * sievert.

After the accident at Chernobyl, the nuclear power debate flared up again. In Sweden the parliament, Riksdagen, made a declaration of intent that reaffirmed an earlier reference for the nuclear phase-out to be completed by 2010 and gave a timetable for early decommissioning of two reactors. The timetable decisions were later reversed, but the two units in Barsebäck were eventually halted (in 1999 and 2005, respectively) mainly because their proximity to-and the resultant pressure from-the Danish capital Copenhagen.

In Italy the power reactors were stopped in a decision in 1988 after a referendum 1987.

\subsection{The Fukushima Accident and Radiological Impact}

\subsubsection{The Accident}

The accident, which took place at the Fukushima Daiichi site on March 11, 2011, was the second accident ever to be reported in the highest category (7) on the INES scale (International Nuclear and Radiological Event Scale) for a civilian nuclear power reactor. The cause was a combination of an earthquake and a subsequent tsunami. The details of the accident are reported elsewhere in this publication. As in Chernobyl, a large-scale local evacuation (tens of kilometers) has taken place, combined with large scale, national control of foodstuffs and drinking water.

\subsubsection{The Size of the Radiological Impact Outside Japan}

Geographical and meteorological factors and the features of the accident determine its long-range radiological impact. By comparison, the extreme height of the Chernobyl accident's plume accounted for much of its higher long-range effects. In Korea, the maximum air concentration of Cs-137 after the Fukushima accident was around $3 \mathrm{mBq} / \mathrm{m}^{3}$, about 100 times lower than the highest corresponding concentration measured in Sweden [2,3] after Chernobyl. The EPA's monitoring in the U.S. after Fukushima presented similar values as Korea (around $3 \mathrm{mBq} / \mathrm{m}^{3}$ or $\left.0.1 \mathrm{pCi} / \mathrm{m}^{3}\right)$. 


\subsection{Technical Assessments and Stress Tests in Europe}

\subsubsection{IAEA Reports}

The IAEA issues regular Status Reports to the public on the current status of the Fukushima Daiichi Nuclear Power Plant, which includes information on environmental radiation monitoring, the status of workers, and current conditions on-site at the plant. While information such as IAEA's has been given on a regular basis after the accident, more complete reports have been in preparation for several years, leaving a few years' vacuum or gap in the more detailed public technical discussion for those not directly involved with the assessments.

A comprehensive report from the IAEA will be finalized by year-end 2014. The report contains details from five subgroups covering the areas:

1. A description of the accident as it unfolded, "what happened";

2. Safety assessment;

3. Emergency preparedness and response and "lessons learned";

4. Assessment of the radiological consequences to humans and biota; and

5. Post-accident assessment.

\subsubsection{The European Union}

The European Union (EU) nuclear regulators group (ENSREG) and the European Commission (EC) have carried out stress tests for all reactors in the EU and a number of others (Switzerland and Ukraine, both of which fully participated in the EU stress tests according to the Commission, and Armenia, Turkey, Russia, Taiwan, Japan, South Korea, South Africa, and Brazil). The initiating events studied were earthquakes and flooding.

The initial request was made by the European Council on March 25, 2011 and reports were finalized in 2012 with the lengthy title "Technical summary on the implementation of comprehensive risk and safety assessments of nuclear power plants in the EU, accompanying the document communication from the commission to the council and the European Parliament on the comprehensive risk and safety assessments ("stress tests") of nuclear power plants in the EU and related activities."

While both the published EC report and the expected IAEA 2014 report will probably be valuable in boosting discussion on all aspects of nuclear safety, the political impact may not be dependent solely on the technical reports, partly because no drastic conclusions are made or expected and partly because many politicians' opinions have been more or less fixed during the last decades. 


\subsection{Political Impact in Europe from Fukushima}

For reasons given above, the Fukushima Daiichi accident may be expected to produce a more general debate outside Japan, somewhat similar to the political impact from Three Mile Island. The U.S. has never had any major radiological consequences from nuclear accidents, but in Europe, the memory from Chernobyl is still close enough to be remembered by many. One could therefore speculate that the reaction would be stronger in Europe. In any case, the most articulate reactions came in Germany and Italy.

German energy production plans have replaced one political sensitive production method (nuclear energy) by another (dependency of Russian gas) and have lived with criticism since the first steps of this transition were taken. According to the magazine The Economist, "Germany ... under its new chancellor, Angela Merkel, has been far too keen on bilateral deals, such as the building of a new under-sea pipeline, heedless of the concerns of its nearest eastern neighbors" (May 11, 2006). In Germany, the latest version of a nuclear phase-out was decided, clearly attributable to the Fukushima accident, to be complete and to occur within 11 years. The corresponding earlier Swedish decision was made after the startup of the units Ringhals and Forsmark 3, assumed at the time of the parliamentarian announcement to have (or be given) a 25 -year lifetime. The Swedish position was modified but the much shorter time to the deadline in Germany makes it much more difficult to reverse the decision.

In Italy a court ruling decided in January 2011 that a referendum might validate a change in legal requirements and start planning for nuclear power. It may seem a strange time for the Italian government to ask for such support, but it was the result of a process that had started much earlier. (The question was also awkwardly formulated requiring a yes vote to vote against the nuclear plans, i.e., yes to change existing legal anti-nuclear requirements.)

In contrast to Germany and Italy, Finland and to some extent Sweden represent a trend towards nuclear energy. In Finland the building of a new reactor is well underway, despite a considerable delay. The decision-in-principle was taken in 2002. In Sweden an amendment of the Nuclear Activities Act and the Environmental Code came into force on January 1, 2011. The new legislative amendment makes it possible to gradually replace existing nuclear power reactors with new nuclear power reactors.

Partly because decisions were already made, there was no discussion about the wisdom of nuclear power related to an imminent decision, which could be spurred by the Fukushima accident and that probably influenced the debate climate. In Sweden, the Vattenfall Company submitted on July 31, 2012 a pro forma application to build a new reactor, and the environmental impact consultation process started formally in January 2014. 


\subsection{Influence of Green Politics in Europe}

In the final analysis, whatever psychological explanation one might seek out, perhaps the influence of environmental issues in European politics is the most important factor in understanding the European response to Fukushima. Green, in Europe denoting anti-nuclear, parties are influential in most European countries and environmentalism also strongly pervades many other parties such as the German social democrats. Heated nuclear debates have been long-standing features in Austria, Sweden, and Germany with important influence on the political scene, both before and after the TMI, Chernobyl, and Fukushima accidents.

The European responses such as the German and Italian dramatic decisions should not be seen solely as a political reflex attributable to the Fukushima accident alone. It does reflect a reinforced concern for safety, but this is superimposed on a delicate balance, with long histories and trends, for nuclear policies between European popular views and parliamentary positions.

Open Access This chapter is distributed under the terms of the Creative Commons Attribution Noncommercial License, which permits any noncommercial use, distribution, and reproduction in any medium, provided the original author(s) and source are credited.

\section{References}

1. The United Nations Scientific Committee on the Effect of Atomic Radiation, UNSCEAR (2008) Ionizing radiation, sources and effect of ionizing radiation. Report to the General Assembly, with Scientific Annexes, Volume II, Scientific Annexes C, D and E

2. OECD/NEA (2011) Report of the Korean Government, Response to the Fukushima Daiichi Nuclear Accident to OECD/NEA

3. SSI (2007) The radiation environment in Sweden, SSI Report 2007:02 (in Swedish) 